\title{
MicroRNA signatures as clinical biomarkers in lung cancer
}

This article was published in the following Dove Press journal:

Current Biomarker Findings

27 May 2015

Number of times this article has been viewed

\section{Athina Markou \\ Martha Zavridou \\ Evi S Lianidou}

Analysis of Circulating Tumor Cells, Lab of Analytical Chemistry, Department of Chemistry, University of Athens, Athens, Greece
Correspondence: Evi Lianidou Analysis of Circulating Tumor Cells, Laboratory of Analytical Chemistry, Department of Chemistry, University Campus, University of Athens, Athens, I577I, Greece

Tel 00302107274311

Fax 00302107274750

Email lianidou@chem.uoa.gr
Abstract: Even if early lung cancer detection has been recently significantly improved, the invasive nature of current diagnostic procedures, and a relatively high percentage of false positives, is limiting the application of modern detection tools. The discovery and clinical evaluation of novel specific and robust non-invasive biomarkers for diagnosis of lung cancer at an early stage, as well as for better prognosis and prediction of therapy response, is very challenging. MicroRNAs (miRNAs) can play an important role in the diagnosis and management of lung cancer patients, as important and reliable biomarkers for cancer detection and prognostic prediction, and even as promising as novel targets for cancer therapy. miRNAs are important in cancer pathogenesis, and deregulation of their expression levels has been detected not only in lung cancer but in many other human tumor types. Numerous studies strongly support the potential of miRNAs as biomarkers in non-small-cell lung cancer, and there is increasing evidence that altered miRNA expression is associated with tumor progression and survival. It is worth mentioning also that detection of miRNAs circulating in plasma or serum has enormous potential, because miRNAs serve as non-invasive biomarkers not only for the diagnosis and prognosis of the disease, but also as novel response and sensitivity predictors for cancer treatment. In this review, we summarize the current findings on the critical role of miRNAs in lung cancer tumorigenesis and highlight their potential as circulating biomarkers in lung cancer. Our review is based on papers that have been published after 2011, and includes the key words "miRNAs" and "lung cancer".

Keywords: non-small-cell lung carcinoma, miRNAs, tumor biomarkers, circulating miRNAs, liquid biopsy, exosomes

\section{Introduction}

Lung cancer is the leading cause of cancer-related deaths worldwide, and numerous ongoing research efforts are directed to identify new strategies for its early detection, since early detection and precise diagnosis are critical for patients. Despite years of research, the prognosis for patients with lung cancer remains poor. The diagnosis of non-small-cell lung carcinoma (NSCLC) at an early stage, as well as better prediction of outcome, remains clinically challenging due to the lack of specific and robust non-invasive biomarkers. ${ }^{1}$ Recent diagnostic procedure advances have considerably improved early lung cancer detection. However, the invasive, unpleasant, and inconvenient nature of current diagnostic procedures limits their application. Moreover, current screening methods still lead to a high percentage of false positives. Thus, there is still a great need for novel noninvasive biomarkers for early lung cancer diagnosis. 
Lung cancers are classified according to the histological types, and this classification has important implications for the clinical management and prognosis of the disease. ${ }^{2}$ There are two main histological groups of lung cancer including NSCLC (85\%) and small cell lung cancer (15\%). NSCLC comprises three major histological subtypes: adenocarcinoma (AD), squamous cell carcinoma (SCC), and large cell carcinoma. ${ }^{3}$

Increasing evidence suggests that microRNAs (miRNAs) can play an important role in the diagnosis and management of lung cancer patients. Recent studies have indicated that miRNAs are important gene regulators that play critical roles in biological processes. Therefore, the expression levels of miRNAs can be important and reliable biomarkers for cancer detection and prognostic prediction, and may even potentially serve as targets for cancer therapy.,

Non-invasive blood-based biomarkers for cancer detection and follow-up are very promising and offer a very attractive approach for improving the outcome of cancer patients. Recently, the number of groups that are working worldwide toward establishing a "liquid biopsy" approach for following up a variety of types of solid cancer is constantly increasing. The liquid biopsy approach is based on the enumeration and molecular characterization of circulating tumor cells, ${ }^{6-8}$ and on the detection of specific DNA sequences in cell-free circulating tumor DNA, ${ }^{9}$ as well as on circulating miRNAs, ${ }^{10}$ as a source of valuable biomarkers.

Today, 12 years after the first connection between miRNAs and cancer was revealed by Calin et al, ${ }^{11}$ it seems that miRNAs are important players that could combine the pieces of the huge cancer puzzle. A plethora of human miRNAs has been discovered since then, and their critical role as key players in metastasis has begun to be elucidated. ${ }^{12}$ It is now clear that miRNAs are the double face of the same coin, as they seem to control metastasis in various cancers either as metastasis-suppressive miRNAs or as metastasispromoting miRNAs.

miRNAs can play an important role in the diagnosis and management of lung cancer patients, as important and reliable biomarkers for detection and prognosis. Moreover, nowadays, miRNAs are even promising as novel targets for cancer therapy, since they are important in cancer pathogenesis. Deregulation of their expression levels has been detected not only in lung cancer, but also in many other human tumor types. Numerous studies strongly support the potential of miRNAs as biomarkers in NSCLC, and there is increasing evidence that altered miRNA expression is associated with tumor progression and survival. It is worth mentioning also that detection of miRNAs circulating in plasma or serum has enormous potential, because miRNAs serve as non-invasive biomarkers not only for the diagnosis and prognosis of the disease, but also as novel response and sensitivity predictors for cancer treatment.

In this review, we summarize the current findings on the critical role of miRNAs in lung cancer tumorigenesis and highlight their potential as circulating biomarkers in lung cancer. Our review is based on papers that have been published after 2011, and includes the key words "miRNAs" and "lung cancer".

\section{mRNAs, lung carcinogenesis, and metastasis}

Many groups till now have intensively investigated the role of miRNAs in lung cancer. ${ }^{13-16}$ In this type of cancer, it is becoming clear that circulating miRNAs are suitable to discriminate malignant from non-malignant tissue. ${ }^{17}$ Using miRNA expression profiles, Lu et al correctly classified poorly differentiated tumors with better accuracy than messenger RNA profiles, ${ }^{18}$ while in another study miRNA profiling was shown to predict patient outcome with high accuracy. ${ }^{19}$

Peng et al have recently shown that miR-486 was the most down-regulated miRNA in stage 1 NSCLC tumors when compared to adjacent non-cancerous lung tissues, suggesting that its loss may be important in lung cancer development. ${ }^{20}$ According to this study, this miRNA is a potential biological link to $\mathrm{p} 53$, since it directly targets components of insulin growth factor (IGF) signaling, including insulin-like growth factor 1 (IGF1), IGF1 receptor (IGF1R), and phosphoinositide-3-kinase, regulatory subunit 1 (alpha) (PIK3R1, or p85a) and functions as a potent tumor suppressor of lung cancer both in vitro and in vivo. ${ }^{20}$

Different members of the let-7 family have been reported to be decreased in human lung tumors. Low levels of let- $7 \mathrm{c}$ were significantly associated with metastasis, venous invasion, advanced TNM stages, and poor survival of NSCLC patients. ${ }^{21}$ Ectopic expression of let-7c suppressed the migration and invasion of highly metastatic cells, while its inhibition in cells with relatively low metastatic potential promoted their motility and invasion. ${ }^{21}$

It was also very recently shown that low miR-638 and high SOX2 levels were associated with tumor size and metastasis of NSCLC patients, mainly by modulating the expression levels of markers of epithelial-to-mesenchymal transition. ${ }^{22}$ miR-143 was also found down-regulated in NSCLC tissues, and in vitro experiments have shown that it could significantly suppress the migration and invasion of NSCLC cell lines through targeting CD44v3. ${ }^{23}$ 
Understanding the mechanisms responsible for TNF (tumor necrosis factor)-related apoptosis inducing ligand (TRAIL) resistance is important for the development of anticancer therapies. The miR-34 family consists of tumorsuppressive miRNAs. Recently, it has been reported that miR-34a and miR-34c, which target platelet-derived growth factor receptor alpha and beta (PDGFR- $\alpha$ and PDGFR- $\beta$ ), cell surface tyrosine kinase receptors were down-regulated in lung tumors, compared to normal tissues. ${ }^{24}$ Moreover, overexpression of miR-34a/c or down-regulation of PDGFR- $\alpha / \beta$ by small interfering RNAs, strongly augmented the response to TRAIL, while reducing migratory and invasive capacity of NSCLC cells. ${ }^{24}$ The ERK1/2 pathway and BIM expression were recently linked through miR-494, which was the most down-regulated miRNA after ERK1/2 inactivation. ${ }^{25}$ This miRNA-induced TRAIL resistance in NSCLC through the down-modulation of BIM. ${ }^{25}$ The same group has recently demonstrated that there is a biological link between epidermal growth factor receptor (EGFR) and MET (the receptor tyrosine kinase for hepatocyte growth factors), and the miRNA cluster $23 \mathrm{a} \sim 27 \mathrm{a} \sim 24-2 .^{26}$

\section{miRNAs as biomarkers in NSCLC primary tumor tissues}

Several groups have already studied the association of miRNA expression with prognosis and progression in NSCLC. ${ }^{27}$ The prognostic value of mature miR-21 in NSCLC was firstly shown in $2008 .{ }^{28}$ It was recently shown that advanced stage tumors expressed significantly higher levels of miR-21, compared with TNM stage I tumors, but high levels of miR-21 were associated with worse cancer-specific mortality and relapse-free survival independently of other clinical factors. ${ }^{29}$ By using the Illumina technology, two miRNA signatures that are highly predictive of recurrence/relapse-free survival of stage I NSCLC were identified. ${ }^{30}$

$\mathrm{Hu}$ et al have very recently shown that the expression level of miR-128 was significantly down-regulated in NSCLC tissues and cancer cells, and that this was significantly correlated with NSCLC differentiation, pathological stage, and lymph node metastasis. ${ }^{31}$ Their findings suggest that miR-128 could play a role in NSCLC tumorigenesis, at least in part by modulation of angiogenesis and lymphangiogenesis through targeting vascular endothelial growth factor C, and could simultaneously block ERK, AKT, and p38 signaling pathways. Therapeutic strategies to restore miR-128 in NSCLC could be useful to inhibit tumor progression. ${ }^{31}$ Several aberrantly expressed miRNAs that can discriminate lung ADs from normal lung tissue and are differentially expressed between EGFR-mutated and EGFR wild-type lung ADs have been recently identified. ${ }^{32}$ These miRNAs may be potential biomarkers for early detection and even lung cancer classification. Conventional histopathological methods sometimes cannot distinguish between primary and metastatic ADs in the lung; miRNA profiles can predict the histology of primary lung carcinomas, and differentiate between primary lung ADs and colorectal cancer metastases. ${ }^{33}$

miR-31 is up-regulated in lung AD tissues from patients with lymph node metastases and is a significant predictor of survival..$^{34}$ In vitro functional assays have shown that this miRNA increases cell migration, invasion, and proliferation in an ERK1/2 signaling-dependent manner. ${ }^{34}$ The identification of miRNA-dependent transcriptional regulation differences between SCC and AD histological lung cancer subtypes may provide new biomarkers for personalized treatment strategies..$^{35}$ The expression study of specific miRNAs, and their relationship with clinical-pathological features have been also investigated in NSCLC. Sun et al showed that miR-150 was down-regulated preferentially in subgroups of patients with a tumor diameter more than or equal to $3 \mathrm{~cm}$, in smokers and in stage III and IV tumors. ${ }^{36}$ Moreover, miR-150 and miR-3940-5p expression was decreased in nuclear cell proliferation antigen Ki-67-positive NSCLC cases. miR-150 and miR-3940-5p were found to be significantly down-regulated in p53 immunohistochemistrypositive NSCLC cases, and were negatively correlated with p53 mRNA. ${ }^{36}$

A comprehensive meta-analysis of 20 published miRNA expression studies in lung cancer, identified an miRNA meta-signature of seven miRNAs that were up-regulated (miR-21, miR-210, miR-182, miR-31, miR-200b, miR205, and miR-183) and eight that were down-regulated (miR-126-3p, miR-30a, miR-30d, miR-486-5p, miR-451a, miR-126-5p, miR-143, and miR-145). These miRNAs cooperatively target functionally related and biologically relevant genes in signaling and developmental pathways. ${ }^{37}$ High expression of miR-21 is associated with worse overall survival (OS) in NSCLC, and recurrence/relapse-free survival/cancer-specific survival in lung $\mathrm{AD}$ according to another meta-analysis. ${ }^{38}$ In Table 1 we summarize the prognostic significance of miRNAs as evaluated so far in NSCLC primary tumor tissues.

\section{Evaluation of miRNAs as biomarkers in NSCLC primary tissues and paired serum samples}

Recently, a number of studies performed in primary tissues and paired serum samples focused on the clinical significance 
of miRNAs in NSCLC. In most of these studies, reverse transcription quantitative polymerase chain reaction (RTqPCR) remains the method of choice for the evaluation of miRNA expression in clinical samples. Zhu et al studied the expression levels of miR-96, miR-182, and miR-183 in paired samples from lung cancer patients and in serum samples from normal volunteers and lung cancer cell lines by RT-qPCR. ${ }^{39}$ They have shown that high expression levels of tumor and serum miR-183 were associated with poor OS and may be considered potential novel diagnostic and prognostic lung cancer biomarkers. ${ }^{39}$ The same group has also shown that the expression levels of miR-21, miR-141, and miR-200c in NSCLC were higher than those in normal tissues and that overexpression of serum miR-21 was strongly associated with lymph node metastasis and advanced clinical stage of NSCLC. ${ }^{40}$

When liquid bead array technology (Luminex ${ }^{\mathrm{TM}}$ ) was used to check the expression of 320 mature miRNAs in a pilot testing group of 19 matched fresh-frozen cancerous and non-cancerous tissues from NSCLC patients, eight miRNAs (miR-21, miR-30d, miR-451, miR-10a, miR-30e-5p, and miR-126*, miR-126, and miR-145) were found to be differentially expressed, and these results were further verified by RT-qPCR. ${ }^{41}$ However, in corresponding NSCLC plasma samples, only three of these miRNAs (miR-21, miR-10a, and miR-30e-5p) displayed differential expression. According to the findings of this study, high expression of miR-21 was associated with disease-free interval and OS both in NSCLC tissues and plasma, while low expression of miR-10a in NSCLC plasma samples was associated with worse diseasefree interval and high expression of miR-30e-5p was found to be associated with shorter OS. ${ }^{41} \mathrm{Zhu}$ et al have shown that when the expression of miR-125a-5p, let-7e, miR-30a, miR-30e, and miR-30e-3p in paired tissue and serum samples from NSCLC patients was evaluated it was found that reduced expression of miR-125a-5p, let-7e, and miR-30e was strongly associated with NSCLC dedifferentiation, while no expression of miR-125a-5p and let-7e was associated with shorter OS, and let-7e was an independent prognostic factor. ${ }^{42}$ Another study of the same group has shown that miR-29c and miR-93 expression levels were up-regulated in NSCLC tissues, ${ }^{43}$ while in serum miR-29c was up-regulated, miR-429 was downregulated and miR-429 was associated with poor OS. ${ }^{43}$

Li et al obtained miRNA expression profiles and corresponding clinical information for 372 lung AD patients from The Cancer Genome Atlas (TCGA), and identified the most significantly altered miRNAs between tumor and normal samples. ${ }^{44}$ Using survival analysis and supervised principal components method, they identified an eight-miRNA signature for the prediction of OS of lung AD patients. This miRNA signature, if validated in other prospective studies, may have important implications in clinical practice, in particular identifying a subgroup of patients with LUAD who are at high risk of mortality. ${ }^{44}$

By using next generation sequencing, Ma et al studied the profile of miRNAs in eight lung tumor tissues and identified 896 known miRNAs and 14 novel miRNAs. A panel of four of these miRNAs (miRs-944, 205-3p, 135a-5p, and 577) was identified that could differentiate SCC from AD with $93.3 \%$ sensitivity and $86.7 \%$ specificity. ${ }^{45}$

\section{Circulating miRNAs as NSCLC biomarkers}

Circulating miRNAs comprise a source of highly promising molecular biomarkers that can be easily accessible in various body fluids and offer a novel, non-invasive, cost-effective, and useful tool for cancer detection and prognosis. ${ }^{46-49}$ The extraction and quantification of cell-free miRNAs, circulating in plasma and serum, was firstly shown in 2008 by Mitchell et al. ${ }^{50}$ Since then, numerous studies have shown that miRNAs are rapidly released into the circulation. ${ }^{46-49}$ Changes in plasma miRNA-ratios can indicate early deregulation of tumor-related miRNAs and can even identify miRNA signatures of diagnostic and prognostic value.

The growing interest in developing assays for circulating miRNAs necessitates careful consideration of pre-analytical and analytical parameters on their isolation, stability, and quantification. Especially the use of exogenous and endogenous controls for normalization of data is very critical for the reliable quantification of circulating miRNA levels in plasma. According to a recent study, endogenous circulating miRNA levels are unstable when plasma is stored at $4^{\circ} \mathrm{C}$, and samples should be kept at $-70^{\circ} \mathrm{C}$, where the extracted miRNAs remain stable for up to 1 year. ${ }^{51}$ Normalization based on combined endogenous and exogenous control miRNAs can correct for differences in miRNA recovery and complementary DNA synthesis between samples. ${ }^{51}$

Moreover, the quantity of residual platelets and microparticles remaining after plasma processing might impact miRNA measurements. Cheng et al report a major effect of plasma processing on the quantification of circulating miRNA levels, and that the majority of detectable miRNAs is substantially affected by sample processing alone. ${ }^{52}$ They suggest that platelet contamination in archived samples 
could largely be eliminated by additional centrifugation, and provide specific practical recommendations for circulating miRNA analysis. ${ }^{52}$

It is also important to mention that according to a recent study, the expression levels of specific miRNAs in serum and plasma could not be the same. More specifically, Heegaard et al studied in paired serum and plasma samples from patients with early stage NSCLC $(n=220)$ and matched controls $(n=220)$ the expressions of seven miRNAs (miR-146b, miR-221, let-7a, miR-155, miR-17-5p, miR-27a, and miR-106a) and reported that in serum, miRNA expression levels did not correlate well with corresponding levels in plasma. ${ }^{53}$

Next generation sequencing of small RNAs holds also a great potential to quantify miRNAs in peripheral blood and to identify previously unknown miRNAs serving as lung cancer biomarkers. By using the high-throughput SOLiD system, Keller et al performed transcriptome sequencing of all known miRNAs, and were the first to detect 41 novel mature forms of known miRNA precursors in the peripheral blood of lung cancer patients. ${ }^{54}$

\section{Circulating miRNAs in plasma and serum as prognostic biomarkers}

Serum miRNAs could serve as predictors of survival for advanced NSCLC. Wang et al recently identified transforming growth factor- $\beta$ signaling pathway-related serum miRNAs as predictors of survival in advanced NSCLC. They checked 140 miRNAs that were highly expressed in serum, and found that high expression of miR-16 in serum was associated with a significantly better survival..$^{55}$ They were able to identify patients at the highest risk of death by using a combined 17-miRNA risk score. ${ }^{55}$ When the expression levels of miR-19a were evaluated in paired tissue and serum samples of NSCLC patients, it was found that overexpression of miR-19a in serum could indicate an independent, poor prognostic factor for survival in NSCLC patients. ${ }^{56}$

NSCLC patients could be distinguished from healthy donors by using an eleven-plasma miRNA signature, while another six-plasma miRNA signature was able to discriminate between patients with NSCLC and patients with chronic obstructive pulmonary disease.$^{57}$ More specifically, high miR155-5p, high miR-223-3p, and low miR-126-3p levels were significantly associated with a higher risk for progression in $\mathrm{AD}$ patients, while high miR-20a-5p, low miR-152-3p, and low miR-199a-5p plasma levels significantly predicted survival of SCC patients. ${ }^{57}$ Another potential biomarker in patients with lung cancer is miR-17-5p. Its expression levels in serum were significantly increased in lung cancer patients compared with healthy individuals, and were indicative of shorter survival times. ${ }^{58}$

\section{Circulating miRNAs in plasma and serum as early diagnostic markers for lung cancer}

A variety of miRNAs have been evaluated as biomarkers for early detection of lung cancer. Fortunato et al have recently profiled circulating miRNAs in plasma based on the evaluation of reciprocal miRNA levels measured by RT-qPCR. ${ }^{59}$ To avoid bias due to the release of miRNAs from blood cells, a signature of miRNA ratios distinguishing hemolyzed samples was identified. ${ }^{59}$ Global profiling approaches in serum from patients with AIDS-defining cancer (ADC) of the lung revealed that a group of six miRNAs, (miR-30c-1, miR-616, miR-146b-3p, miR-566, miR-550, and miR-939) was present at substantially higher levels in ADC compared with control sera, while miR-339-5p and miR-656 were detected at substantially lower levels in ADC sera. ${ }^{60}$ According to another study, miRNA-21 expression levels were significantly higher in plasma and exhaled breath condensate samples from patients with a diagnosis of NSCLC in respect to controls, while corresponding levels of miRNA-486 were significantly lower, indicating a potential of these miRNAs to be used as a first-line screening test in high-risk subjects. ${ }^{61}$

Plasma miR-21, miR-145, and miR-155 also have strong potential as biomarkers for early detection of lung cancer, ${ }^{62}$ while levels of miR-328, miR-18a, miR-339, and miR-140 in peripheral blood of NSCLC patients were significantly higher than in blood of healthy donors. ${ }^{63}$ In particular, miR-328 plasma levels could be used to correctly discriminate between patients with early NSCLC and healthy donors. ${ }^{63}$ Additionally, in another study, miR-155, miR-197, and miR-182 levels in plasma of lung cancer patients (including stage I) were found to be significantly elevated compared with controls. ${ }^{64}$ Moreover, miR-155 and miR-197 plasma levels were higher in patients with verified metastasis, and were significantly decreased in patients eho responded to chemotherapy. ${ }^{64}$

The potential of aberrant expression of miR-21 has been explored intensively in lung cancer. A recent meta-analysis systematically investigated whether the expression of this single miRNA could correctly distinguish patients with lung cancer from cancer-free controls with a high level of diagnostic accuracy; 676 patients with lung cancer and 529 healthy controls were involved, and it was reported that 
a single miRNA, even if this is miR-21, is not sufficient to identify lung cancer, and that more miRNAs should be used. ${ }^{65}$ Another recent meta-analysis that was based on a systematic search in several research databases for studies of the accuracy of circulating miRNAs as diagnostic indicators of lung cancer, and based on 13 publications, came to the conclusion that circulating miRNAs show significant potential as diagnostic markers of lung cancer. However, larger, more rigorous studies are needed to confirm such a diagnostic role. ${ }^{66}$

Bianchi et al developed a test, based on the detection of 34 circulating miRNAs' signature from plasma, which is able to identify high-risk individuals with early lung cancer with $80 \%$ accuracy. ${ }^{67}$ This signature could assign disease probability either in asymptomatic or symptomatic patients, since it is able to distinguish between benign and malignant lesions, and to capture the onset of the malignant disease in individual patients over time. ${ }^{67}$ In Tables $2-4$ we summarize the findings of recent studies on circulating miRNAs in lung cancer. More specifically, in Table 2 we summarize the findings of recent studies on circulating miRNAs in plasma, in Table 3 we summarize the findings of recent studies on circulating miRNAs in serum, and in Table 4 we summarize the findings of recent studies on circulating miRNAs in whole blood of patients with lung cancer.

Table I Prognostic significance of miRNA signatures in lung cancer primary tumor tissues

\begin{tabular}{|c|c|c|c|}
\hline miRNAs studied & Reported findings & Clinical samples & Ref \\
\hline $\begin{array}{l}\text { hsa-miR-2I, hsa-miR-3I, hsa-miR-34a, } \\
\text { hsa-miR-2,* hsa-miR-504, } \\
\text { hsa-miR-I8a, and hsa-miR-4I2 }\end{array}$ & $\begin{array}{l}\text { High-level expression of miR-2 I was significantly } \\
\text { correlated with shortened survival time } \\
(P=0.022 \text {, log-rank test; Kaplan-Meier })\end{array}$ & Four matched pairs of tissues & 27 \\
\hline miR-2I and miR-205 & $\begin{array}{l}\text { miR-2I overexpression correlated with OS } \\
(P=0.027) \text {, overexpression of mature miR-205 } \\
\text { did not correlate with OS }\end{array}$ & $\begin{array}{l}46 \text { pairs of surgically removed NSCLC } \\
\text { primary tumor tissues and their } \\
\text { corresponding normal lung tissues }\end{array}$ & 28 \\
\hline miR-2I, miR-I7, and miR-I55 & $\begin{array}{l}\text { Elevated miR-2I (HR 2.06, } 95 \% \mathrm{Cl} \mathrm{I} . \mathrm{I} 3-3.75) \text {, miR-I7 } \\
\text { (HR 2.00, I.I0-3.6I), and miR-I55 (HR 2.37, } \\
\text { I.27-4.42) was associated with worse } \\
\text { cancer-specific mortality }\end{array}$ & $\begin{array}{l}317 \text { NSCLC primary tumor tissues } \\
\text { (FFPEs) }\end{array}$ & 29 \\
\hline miRNA profiling study & $\begin{array}{l}\text { I } 84 \text { miRNAs were associated with RFS in } \\
\text { the adjusted analyses with } P=0.05 \text { but not } \\
\text { significant in global tests (FDR, } 0.05 \text { ) }\end{array}$ & $\begin{array}{l}357 \text { stage I NSCLC FFPE primary } \\
\text { tumor tissues }\end{array}$ & 30 \\
\hline miR-3I & $\begin{array}{l}\text { High miR-3I expression is associated with } \\
\text { adverse outcome in patients with T2N0 lung } \\
\text { ADC (log-rank, } P=0.0194 \text { ) }\end{array}$ & $\begin{array}{l}64 \text { frozen lung ADC primary tumor } \\
\text { tissues }\end{array}$ & 34 \\
\hline $\begin{array}{l}\text { miR-150, miR-18b-5p, miR-643, } \\
\text { and miR-3940-5p }\end{array}$ & $\begin{array}{l}\text { miR-I } 50 \text { and miR-3940-5p were found to be } \\
\text { significantly down-regulated in } p 53 \text { IHC-positive } \\
\text { NSCLC cases and were negatively correlated } \\
\text { with p53 }\end{array}$ & 90 NSCLC primary tumor tissues & 36 \\
\hline miR-2I and miR-I55 & $\begin{array}{l}\text { miR-I55, the pooled HR for OS was } 2.09 \\
(95 \% \text { Cl: } 0.68-6.4 I, P>0.05)\end{array}$ & $\begin{array}{l}88 \text { fresh-frozen NSCLC primary } \\
\text { tumor tissues }\end{array}$ & 38 \\
\hline miR-96, miR- 182 , and miR- 183 & $\begin{array}{l}\text { miR- } 183 \text { Family were associated with overall } \\
\text { poor survival in patients with lung cancer }\end{array}$ & $\begin{array}{l}70 \text { paired samples from lung cancer } \\
\text { patients }\end{array}$ & 39 \\
\hline $\begin{array}{l}\text { miR-2I, miR-30d, miR-45I, miR-10a, } \\
\text { miR-30e-5p and miR-I26,* miR-I26, } \\
\text { miR-I45 }\end{array}$ & $\begin{array}{l}\text { Low expression of miR-I0a in NSCLC plasma } \\
\text { samples was associated with worse DFI }(P=0.050) \\
\text { and high expression of miR-30e-5p was found to } \\
\text { be associated with shorter OS }(P=0.048)\end{array}$ & $\begin{array}{l}40 \text { pairs of surgically removed NSCLC } \\
\text { primary tumor tissues and their } \\
\text { corresponding normal lung tissues }\end{array}$ & $4 I$ \\
\hline $\begin{array}{l}\text { miR-125a-5p, let-7e, miR-30a, } \\
\text { miR-30e, and miR-30e-3p }\end{array}$ & $\begin{array}{l}\text { miR- } 125 a-5 p \text { and let-7e were associated with } \\
\text { shorter OS }\end{array}$ & $\begin{array}{l}70 \text { pairs of surgically removed NSCLC } \\
\text { primary tumor tissues and their } \\
\text { corresponding normal lung tissues }\end{array}$ & 42 \\
\hline $\begin{array}{l}\text { miR-3I, miR-I96b, miR-766, } \\
\text { miR-5I9a-I, miR-375, miR-I87, } \\
\text { miR-33I, and miR-I0I-I }\end{array}$ & $\begin{array}{l}\text { Patients assigned to the high-risk group exhibited } \\
\text { poor OS compared with patients in the low-risk } \\
\text { group }(H R=I .99, P<0.00 \mathrm{I})\end{array}$ & 372 NSCLC primary tumor tissues & 44 \\
\hline 667 miRNAs & $\begin{array}{l}\text { Nine miRNAs were found to be differentially } \\
\text { expressed in SCC versus adenocarcinoma samples }\end{array}$ & 44 NSCLC primary tumor tissues & 35 \\
\hline 677 miRNAs & $\begin{array}{l}\text { Expression of miR- } 128,-10 b,-502-3 p \text {, and }-192 \\
\text { differed between SCC and AD, and miR- } 128 \text {, } \\
\text { and }-192 \text { between NLP and NSCLC }\end{array}$ & $\begin{array}{l}50 \text { squamous cell carcinoma primary } \\
\text { tumor tissues }\end{array}$ & 67 \\
\hline
\end{tabular}

Abbreviations: miRNA, mircro-ribonucleic acid; hsa-miRNA, Homo sapiens miRNA; ref, reference; OS, overall survival; Cl, confidence interval; HR, hazard ratio; RFS, recurrence/relapse-free survival; NSCLC, non-small-lung carcinoma; SCC, squamous cell carcinoma; NLP, normal lung parenchyma; FDR, false discovery rate; ADR, AIDSdefining cancers; IHC, immunohistochemistry; DFI, disease-free interval; FFPE, formalin-fixed paraffin-embedded; AD, adenocarcinoma. 
Table 2 Circulating miRNAs in serum as biomarkers in lung cancer

\begin{tabular}{|c|c|c|c|}
\hline Clinical samples & miRNAs studied & Reported findings & Ref \\
\hline $\begin{array}{l}70 \text { NSCLC patients as well as in serum } \\
\text { samples from } 48 \text { healthy controls }\end{array}$ & miR-29c, miR-93, and miR-429 & $\begin{array}{l}\text { miR-29 }(A \cup C=0.723) \\
\text { miR-429 }(A \cup C=0.727)\end{array}$ & 43 \\
\hline $\begin{array}{l}40 \text { sera of ADC patients and } 40 \text { age- } \\
\text { and sex-matched controls }\end{array}$ & $\begin{array}{l}\text { miR-30c-I, miR-6I6, miR-I46b-3p, } \\
\text { miR-566, miR-550, miR-939, } \\
\text { miR-339-5p, and miR-656 }\end{array}$ & 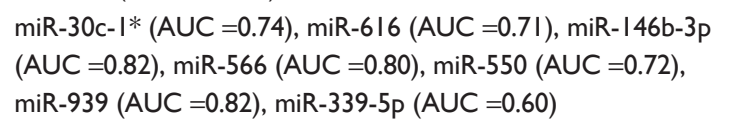 & 48 \\
\hline 391 patients with advanced NSCLC & $\begin{array}{l}\text { Global miRNA microarray } \\
\text { expression profiling }\end{array}$ & $\begin{array}{l}\uparrow \text { miR- } 16 \text { was associated with a significantly better survival } \\
\text { (adjusted } \mathrm{HR}=0.4,95 \% \mathrm{Cl}: 0.3-0.5 \text { ) }\end{array}$ & 55 \\
\hline $\begin{array}{l}\text { 20I NSCLC patients and } 103 \text { healthy } \\
\text { controls }\end{array}$ & $\operatorname{miR}-19 a$ & $\begin{array}{l}\uparrow \text { miR-19a outcome was significantly worse than those of } \\
\text { patients with } \downarrow \text { miR- } 19 \text { a expression ( } \mathrm{HR}=1.438,95 \% \mathrm{Cl} \text {, } \\
\text { I.007-2.052, } P=0.046)\end{array}$ & 56 \\
\hline $\begin{array}{l}221 \text { lung cancer patients and } \\
54 \text { matched controls }\end{array}$ & miR-I7-5p & $\begin{array}{l}\uparrow \text { miR-17-5p expression associated with shorter survival times } \\
(\mathrm{HR}=1.767,95 \% \mathrm{Cl} \quad 1.039-3.005 ; P=0.035)\end{array}$ & 58 \\
\hline $\begin{array}{l}80 \text { sera specimens including those } \\
\text { from ADC patients }\end{array}$ & Global profiling & $\begin{array}{l}\uparrow \mathrm{miR}-30 \mathrm{c}-\mathrm{I} *(A \cup C=0.74 ; P<0.002), \uparrow \mathrm{miR}-6 \mathrm{I} 6^{*}(\mathrm{AUC}=0.7 \mathrm{I} ; \\
P=0.00 \mathrm{I}), \uparrow \mathrm{miR}-\mathrm{I} 46 \mathrm{~b}-3 \mathrm{P}(\mathrm{AUC}=0.82 ; P<0.000 \mathrm{I}), \uparrow \mathrm{miR}-566 \\
(A \cup C=0.80 ; P<0.000 \mathrm{I}), \uparrow \mathrm{miR}-550(\mathrm{AUC}=0.72 ; P=0.0006) \text {, } \\
\text { and } \uparrow \mathrm{miR}-939(\mathrm{AUC}=0.82 ; P<0.000 \mathrm{I})\end{array}$ & 60 \\
\hline $\begin{array}{l}60 \text { NSCLC patients and } 30 \text { healthy } \\
\text { controls }\end{array}$ & $\operatorname{miR}-210$ & $\mathrm{AUC}=0.775(95 \% \mathrm{Cl} 0.690-0.872)$ & 69 \\
\hline
\end{tabular}

Abbreviations: miRNAs, micro-ribonucleic acids; ref, reference; $\mathrm{Cl}$, confidence interval; $\mathrm{AUC}$, area under the curve; HR, hazard ratio; NSCLC, non-small-cell lung carcinoma; ADC, AIDS-defining cancers.

\section{miRNAs as predictive biomarkers}

Individual selection of high-risk patients for adjuvant systemic therapies requires specific and reliable biomarkers, and is extremely important in lung cancer, since almost $50 \%$ of NSCLC patients develop distant metastases following pulmonary resection. The development of targeted therapies based on specific mutations has improved lung cancer management. However, the prognosis still remains poor. MiRNAs are intensively investigated as predictive biomarkers in lung cancer.

Skrzypski et al recently identified three new miRNAs predictive of distant relapse in operable SCC. ${ }^{68}$ More specifically, by using quantitative RT-qPCR they evaluated the expression of 677 miRNAs in fresh-frozen tumor samples in a training cohort of 50 SCC patients with a known clinical outcome and who underwent curative surgery, and then re-evaluated all miRNAs that were found to be associated with highest predictive value for distant relapse in formalinfixed paraffin-embedded material in an independent group of 134 stage I-IIIA SCC patients. When the same miRNAs were investigated in 89 lung $\mathrm{AD}$ patients and in normal lung parenchyma, miR-662, -192, and -192* were confirmed as prognostic biomarkers in the independent SCC cohort, while miR-128, -10b, -502-3p, and -192 were differentially expressed between SCC and AD, and miR-128 and -192between normal lung parenchyma and NSCLC.$^{68}$

Table 3 Circulating miRNAs in plasma as biomarkers in lung cancer

\begin{tabular}{|c|c|c|c|}
\hline Clinical samples & miRNAs studied & Reported findings & Ref \\
\hline 54 patients with lung cancer and 46 controls & miR-2I, miR-486 & Sens $=87 \%$, Spec $=86.5 \%, A \cup C=0.90$ & 61 \\
\hline $\begin{array}{l}\text { A training set of } 62 \text { patients and } 60 \text { healthy } \\
\text { smokers, and a testing set of } 34 \text { malignant } \\
\text { tumor patients; } 30 \text { patients with benign } \\
\text { pulmonary nodules and } 32 \text { healthy smokers }\end{array}$ & miR-2I, miR-I45, miR-I55 & Sens $=76.5 \%$, Spec $=81.3 \%, A \cup C=0.87$ & 62 \\
\hline $\begin{array}{l}220 \text { patients with early stage NSCLC and } \\
220 \text { matched controls }\end{array}$ & $\begin{array}{l}\text { miR-146b, miR-22I, let-7a, miR-I55, } \\
\text { miR-I7-5p, miR-27a, miR-106a, miR-29c }\end{array}$ & $\mathrm{AUC}=0.60$ & 53 \\
\hline $\begin{array}{l}52 \text { patients with I-IIIA stages NSCLC, } \\
\text { I0 patients with COPD }\end{array}$ & $\begin{array}{l}\text { miR-20a-5p, miR-25-3p, miR-I55-5p, miR-19I-5p, } \\
\text { mir-223-3p, miR-296-5p, miR-320-3p, let-7f-5p, } \\
\text { miR-24-3p, miR-126-3p, miR-145-5p, } \\
\text { miR-I52-3p, miR-199a-5p }\end{array}$ & $\begin{array}{l}\uparrow \text { miR- } 155-5 p(P=0.068) \text { and miR-20a-5p } \\
(P=0.018) \text { along with } \downarrow \text { miR- } 152-3 p \\
(P=0.049) \text { were associated with poor DFS } \\
\text { of NSCLC patients }\end{array}$ & 57 \\
\hline $\begin{array}{l}74 \text { lung cancer patients and } 68 \text { age-matched } \\
\text { cancer-free controls }\end{array}$ & miR-I55, miR-197, miR-I82 & Sens $=81.3 \%$, Spec $=86.8 \%, A \cup C=0.90$ & 64 \\
\hline
\end{tabular}

Abbreviations: miRNAs, micro-ribonucleic acids; ref, reference; NSCLC, non-small-cell lung carcinoma; COPD, chronic obstructive pulmonary disease; Sens, sensitivity; Spec, specificity; AUC, area under the curve; DFS, disease-free survival. 
Table 4 Circulating miRNAs in whole blood as biomarkers in NSCLC

\begin{tabular}{|c|c|c|c|}
\hline Clinical samples & miRNAs studied & Reported findings & Ref \\
\hline $\begin{array}{l}86 \text { patients with predominantly early-stage NSCLC } \\
\text { and } 24 \text { healthy donors }\end{array}$ & miR-328 & Sens $=70 \%$, Spec $=83 \%, A \cup C=0.82$ & 63 \\
\hline $\begin{array}{l}22 \text { consecutive patients with advanced NSCLC, } \\
\text { treated with pemetrexed-based chemotherapy and }\end{array}$ & miR-22, miR-24, and miR-34a & $\begin{array}{l}\uparrow \text { miR-22 expression was observed } \\
\text { in patients developing progressive }\end{array}$ & 70 \\
\hline 27 age- and sex-matched healthy controls & & disease $(P=0.03)$ & \\
\hline 22 patients with lung adenocarcinoma and 23 controls & miR-190b, miR-630, miR-942, miR-I284 & Sens $=88 \%$, Spec $=89 \%$ & 71 \\
\hline 64 patients with NSCLC and 26 healthy individuals & miR-I43, miR-I50 & 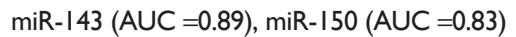 & 72 \\
\hline
\end{tabular}

Abbreviations: miRNAs, micro-ribonucleic acids; NSCLC, non-small-cell lung carcinoma; Sens, sensitivity; Spec, specificity; AUC, area under the curve.

Li et al investigated the levels of miR-210 in serum of patients with NSCLC by using RT-qPCR and determined its predictive value in NSCLC patients following cisplatin-based chemotherapy. ${ }^{69}$ According to their findings, serum miR-210 was up-regulated in patients with NSCLC $(\mathrm{n}=60)$ compared with healthy control subjects $(\mathrm{n}=30)$. Higher serum miR-210 levels were also significantly correlated with the clinical stage and the presence of regional lymph node metastasis in patients with NSCLC. Moreover, the levels of miR-210 in serum of patients who achieved a partial response following cisplatin-based chemotherapy were significantly lower than in patients with stable or progressive disease, and were similar to those in healthy control subjects. ${ }^{69}$

Pemetrexed has been widely used in patients with advanced NSCLC. Franchina et al investigated for the first time the clinical relevance of polymorphisms of folate pathway genes for pemetrexed metabolism. ${ }^{70}$ After evaluating the expression levels of circulating miR-22, miR-24, and miR-34a, they report that miR-22 could represent a novel predictive biomarker for pemetrexed-based treatment, since they found a correlation between high expression of miR-22 in whole blood and the lack of response in pemetrexed-treated NSCLC patients. ${ }^{70}$

The global expression profile of miRNAs in whole blood of 22 patients with lung $\mathrm{AD}$ and 23 controls, ten of whom had a radiographically detected non-cancerous lung nodule and the other 13 of whom were at high risk for developing lung cancer because of a smoking history of $>20$ pack-years, was examined and was based on locked nucleic acid microarrays. ${ }^{71}$ According to this study, which quantified 1,282 human miRNAs, miR-190b, miR-630, miR-942, and miR-1284 were the most frequent constituents of the classifiers generated during the analyses. These results suggest that whole blood miRNA expression profiles can be used to distinguish lung cancer cases from clinically relevant controls. ${ }^{71}$

In conclusion, plasma miRNAs obtained by noninvasive methods could serve as circulating tumor biomarkers of diagnostic, prognostic, and predictive value in NSCLC. However there is still a lot of work to be done before the establishment of miRNA as biomarkers in the clinical laboratory, especially toward the standardization of analytical methodologies used, the inclusion of internal and external controls in each assay, and the consensus toward normalization of these results. In Table 2 we summarize findings presented so far on the detection of circulating miRNAs in plasma and serum of NSCLC patients.

\section{miRNAs in other biofluids as potential biomarkers in lung cancer Sputum}

Sputum miRNAs are potentially useful noninvasive markers for diagnosis of lung cancer. A systematic search for published literature evaluating the diagnostic accuracy of sputum miRNAs in lung cancer was recently performed by Liao et al to determine pooled sensitivity and specificity. Eight studies with a total of 514 patients and 491 controls were included in this meta-analysis. According to the results of this metaanalysis, the diagnostic specificity of sputum miRNAs may be influenced by the miRNA profiles. ${ }^{72}$

The first group who evaluated the expression of miRNAs in sputum was the Jiang laboratory. In their first study, they found that endogenous miRNAs are stably present in sputum specimens, but miR-21 was found to be significantly overexpressed in sputum of NSCLC patients as compared with cancer-free subjects. ${ }^{73}$ Moreover, in the same study it was shown that miR-21 overexpression in sputum was a more sensitive biomarker (70\%) than conventional sputum cytology (48\%) in diagnosing lung cancer.

By using digital PCR, Xie et al reported that combined quantification of miR-31 and miR-210 copy numbers in sputum provided $65.7 \%$ sensitivity and $85.0 \%$ specificity for the diagnosis of stage I NSCLC.${ }^{74}$ Based on this finding, very recently, Li et al reported that by combining miR-31 and miR-210 detection by RT-qPCR and computed tomography, specificity of NSCLC diagnosis was significantly improved. ${ }^{75}$ 


\section{Pleural fluid}

In a recent study, Shen et al examined whether extracellular miRNAs, isolated from pleural fluid, which are deregulated in lung cancer (miR-134, miR-185, and miR-22) can serve as diagnostic markers for lung AD-associated malignant pleural effusion, which has a poor prognosis and is classified as stage IV disease. ${ }^{76}$ By using RT-qPCR they found that the expression of all three miRNAs was significantly lower in LA-MPE than in benign pleural effusions $(P<0.001)$, and they suggest that the expression levels of these circulating extracellular miRNAs (miR-134, miR-185, and miR-22) in patients with pleural effusion may have diagnostic value when differentiating between lung $\mathrm{AD}$-associated malignant pleural effusion and benign pleural effusions. ${ }^{76}$

\section{Exosomes, miRNAs, and lung cancer}

The role of the miRNAs present in tumor-derived exosomes has been intensively exploited in human cancer as a very promising tool for diagnostic and prognostic purposes. ${ }^{77}$ According to very recent findings, exosomes do play an important role, not only as vehicles in the intercellular communication, but also by transferring their content to nearby cells in a process in which they can specifically modulate the surrounding microenvironment, leading to tumor development and progression, which even affected therapy response. ${ }^{78}$

There is intensive research on the elucidation of the role of miRNAs included in exosomes in NSCLC, since very little was known up to now. The significant difference in total exosome and miRNA levels between lung cancer patients and controls, and the similarity between the circulating exosomal miRNA and the tumor-derived miRNA patterns, has been shown already in $2009 .{ }^{79}$ These results firstly suggested that circulating exosomal miRNA might be useful as a screening test for lung AD. In a very recent article, Frydrychowicz et al present a summary of information about the structure and origin of exosomes, and the importance of exosomes, and miRNAs in lung cancer ${ }^{80}$ Recently, Leidinger et al have separately analyzed the miRNome of different immune cell subtypes in lung cancer patients and healthy individuals. They have shown that cancer-specific miRNA expression patterns of whole blood samples are not determined by a single cell type and that additional blood components, like erythrocytes, platelets, or exosomes might contribute to the disease specificity of an miRNA signature.$^{81}$ In another recent study, where the exosomes isolated from bronchoalveolar lavage in patients with lung neoplasm were investigated, it was shown that more exosomes were detected in plasma than in bronchoalveolar lavage..$^{82}$ Based on these studies, information in this field is rapidly growing now, and we strongly believe that information on this very specific topic could be the main theme of another literature review in the near future.

\section{Conclusion}

In conclusion, miRNAs have the potential to serve both as biomarkers and therapeutic agents in cancer, by personalizing diagnosis and therapy ${ }^{83}$ There is increasing evidence that altered miRNA expression is associated with tumor progression and survival in lung cancer patients. Recent data from multiple studies strongly support the potential of miRNAs as biomarkers in NSCLC. Expression profiles of miRNAs were able to distinguish tumors derived from different tissue origins, enabling classification of histologic subtypes of NSCLC. In particular, cell-free miRNAs circulating in body fluids like plasma and serum, today comprise very promising novel tumor biomarkers that will play a critical role in the clinical laboratory in the near future. miRNAs could play an important role for the design of innovative therapies for NSCLC, and by exploiting the unique characteristics of miRNAs, clinicians can come ever closer to achieving the goal of individualized cancer treatment. However, there is still a lot of work to be done before the establishment of miRNAs as biomarkers in the clinical laboratory, especially toward the standardization of analytical methodologies used, the inclusion of internal and external controls in each assay, and the consensus toward normalization of derived data.

\section{Disclosure}

The authors report no conflicts of interest in this work.

\section{References}

1. Herbst RS, Heymach JV, Lippman SM. Lung cancer. $N$ Engl J Med. 2008;359:1367-1380

2. Feinstein AR, Gelfman NA, Yesner R. Observer variability in the histopathologic diagnosis of lung cancer. Am Rev Respir Dis. 1970;101(5): 671-684

3. Travis WD, Travis LB, Devesa SS. Lung cancer. Cancer. 1995;75: 191-202.

4. Van Roosbroeck K, Pollet J, Calin GA. miRNAs and long noncoding RNAs as biomarkers in human diseases. Expert Rev Mol Diagn. 2013; 13(2):183-204

5. Ling H, Fabbri M, Calin GA. MicroRNAs and other non-coding RNAs as targets for anticancer drug development. Nat Rev Drug Discov. 2013;12(11):847-865.

6. Lianidou ES, Strati A, Markou A. Circulating tumor cells as promising novel biomarkers in solid cancers. Crit Rev Clin Lab Sci. 2014;51(3): $160-171$.

7. Alix-Panabières $\mathrm{C}$, Pantel $\mathrm{K}$. Circulating tumor cells: liquid biopsy of cancer. Clin Chem. 2013;59:110-118.

8. Plaks V, Koopman C, Werb Z. Circulating tumor cells. Science. 2013; 341(6151):1186-1188. 
9. Marzese DM, Hirose H, Hoon DS. Diagnostic and prognostic value of circulating tumor-related DNA in cancer patients. Expert Rev Mol Diagn. 2013;13(8):827-844.

10. Schwarzenbach H, Nishida N, Calin GA, Pantel K. Clinical relevance of circulating cell-free microRNAs in cancer. Nat Rev Clin Oncol. 2014;11(3):145-156.

11. Calin GA, Dumitru CD, Shimizu M, et al. Frequent deletions and down-regulation of micro-RNA genes miR15 and miR16 at 13q14 in chronic lymphocytic leukemia. Proc Natl Acad Sci U SA. 2002;99(24): 15524-15529.

12. Ell B, Kang Y. MicroRNAs as regulators of bone homeostasis and bone metastasis. Bonekey Rep. 2014;3:549.

13. Cheng Z, Ma R, Tan W, Zhang L. MiR-152 suppresses the proliferation and invasion of NSCLC cells by inhibiting FGF2. Exp Mol Med. 2014;46:e112.

14. Yu S, Zhang C, Deng F, Zhang Y. miR-99a suppresses the metastasis of human non- small cell lung cancer cells by targeting AKT1 signaling pathway. J Cell Biochem. Epub September 4, 2014.

15. Gu Y, Cheng Y, Song Y, et al. MicroRNA-493 suppresses tumor growth, invasion and metastasis of lung cancer by regulating E2F1. PLoS One. 2014;9(8):e102602.

16. Liu C, Yang H, Xu Z, et al. microRNA- 5481 is involved in the migration and invasion of non-small cell lung cancer by targeting the AKT1 signaling pathway. J Cancer Res Clin Oncol. Epub September 23, 2014.

17. Lodes MJ, Caraballo M, Suciu D, Munro S, Kumar A, Anderson B. Detection of cancer with serum miRNAs on an oligonucleotide microarray. PLoS One. 2009;4(7):e6229.

18. Lu J, Getz G, Miska EA, et al. MicroRNA expression profiles classify human cancers. Nature. 2005;435(7043):834-838.

19. Markou A, Liang Y, Lianidou E. Prognostic, therapeutic and diagnostic potential of microRNAs in non-small cell lung cancer. Clin Chem Lab Med. 2011;49(10):1591-1603.

20. Peng Y, Dai Y, Hitchcock C, et al. Insulin growth factor signaling is regulated by microRNA-486, an underexpressed microRNA in lung cancer. Proc Natl Acad Sci U S A. 2013;110(37):15043-15048.

21. Zhao B, Han H, Chen J, et al. MicroRNA let-7c inhibits migration and invasion of human non-small cell lung cancer by targeting ITGB3 and MAP4K3. Cancer Lett. 2014;342(1):43-51.

22. Xia Y, Wu Y, Liu B, Wang P, Chen Y. Downregulation of miR-638 promotes invasion and proliferation by regulating SOX2 and induces EMT in NSCLC. FEBS Lett. 2014;588(14):2238-2245.

23. Ma Q, Jiang Q, Pu Q, et al. MicroRNA-143 inhibits migration and invasion of human non-small-cell lung cancer and its relative mechanism. Int J Biol Sci. 2013;9(7):680-692.

24. Garofalo M, Jeon YJ, Nuovo GJ, et al. MiR-34a/c-dependent PDGFR- $\alpha / \beta$ downregulation inhibits tumorigenesis and enhances TRAIL-induced apoptosis in lung cancer. PLoS One. 2013;8(6):e67581.

25. Romano G, Acunzo M, Garofalo M, et al. MiR-494 is regulated by ERK1/2 and modulates TRAIL-induced apoptosis in non-small-cell lung cancer through BIM down-regulation. Proc Natl Acad Sci U S A. 2012;109(41):16570-16575.

26. Acunzo M, Romano G, Palmieri D, et al. Cross-talk between MET and EGFR in non- small cell lung cancer involves miR-27a and Sprouty2. Proc Natl Acad Sci U S A. 2013;110(21):8573-8578.

27. Gao W, Shen H, Liu L, Xu J, Xu J, Shu Y. MiR-21 overexpression in human primary squamous cell lung carcinoma is associated with poor patient prognosis. J Cancer Res Clin Oncol. 2011;137(4): $557-566$.

28. Markou A, Tsaroucha EG, Kaklamanis L, Fotinou M, Georgoulias V, Lianidou ES. Prognostic value of mature microRNA-21 and microRNA-205 overexpression in non-small cell lung cancer by quantitative real-time RT-PCR. Clin Chem. 2008;54(10):1696-1704.

29. Saito M, Schetter AJ, Mollerup S, et al. The association of microRNA expression with prognosis and progression in early-stage, non-small cell lung adenocarcinoma: a retrospective analysis of three cohorts. Clin Cancer Res. 2011;17(7):1875-1882.
30. Lu Y, Govindan R, Wang L, et al. MicroRNA profiling and prediction of recurrence/relapse-free survival in stage I lung cancer. Carcinogenesis. 2012;33(5):1046-1054.

31. Hu J, Cheng Y, Li Y, et al. microRNA-128 plays a critical role in human non-small cell lung cancer tumourigenesis, angiogenesis and lymphangiogenesis by directly targeting vascular endothelial growth factor-C. Eur J Cancer. 2014;50(13):2336-2350.

32. Bjaanaes MM, Halvorsen AR, Solberg S, et al. Unique microRNAprofiles in EGFR- mutated lung adenocarcinomas. Int J Cancer. 2014; 135(8):1812-1821.

33. Kim J, Lim NJ, Jang SG, Kim HK, Lee GK. miR-592 and miR-552 can distinguish between primary lung adenocarcinoma and colorectal cancer metastases in the lung. Anticancer Res. 2014;34(5):2297-2302.

34. Meng W, Ye Z, Cui R, et al. MicroRNA-31 predicts the presence of lymph node metastases and survival in patients with lung adenocarcinoma. Clin Cancer Res. 2013;19(19):5423-5433.

35. Molina-Pinelo S, Gutiérrez G, Pastor MD, et al. MicroRNA-dependent regulation of transcription in non-small cell lung cancer. PLoS One. 2014;9(3):e90524.

36. Sun Y, Su B, Zhang P, et al. Expression of miR-150 and miR-3940-5p is reduced in non-small cell lung carcinoma and correlates with clinicopathological features. Oncol Rep. 2013;29(2):704-712.

37. Võsa U, Vooder T, Kolde R, Vilo J, Metspalu A, Annilo T. Metaanalysis of microRNA expression in lung cancer. Int $J$ Cancer. 2013;132(12):2884-2893.

38. Yang M, Shen H, Qiu C, et al. High expression of miR-21 and miR-155 predicts recurrence and unfavourable survival in non-small cell lung cancer. Eur J Cancer. 2013;49(3):604-615.

39. Zhu W, Liu X, He J, Chen D, Hunag Y, Zhang YK. Overexpression of members of the microRNA-183 family is a risk factor for lung cancer: a case control study. BMC Cancer. 2011;11:393.

40. Liu XG, Zhu WY, Huang YY, et al. High expression of serum miR-21 and tumor miR-200c associated with poor prognosis in patients with lung cancer. Med Oncol. 2012;29(2):618-626.

41. Markou A, Sourvinou I, Vorkas PA, Yousef GM, Lianidou E. Clinical evaluation of microRNA expression profiling in non-small-cell lung cancer. Lung Cancer. 2013;81(3):388-396.

42. Zhu WY, Luo B, An JY, et al. Differential Expression of miR-125a-5p and let-7e predicts the progression and prognosis of non-small-cell lung cancer. Cancer Invest. 2014;32(8):394-401.

43. Zhu W, He J, Chen D, et al. Expression of miR-29c, miR-93, and miR-429 as potential biomarkers for detection of early stage non-small lung cancer. PLoS One. 2014;9(2):e87780.

44. Li X, Shi Y, Yin Z, Xue X, Zhou B. An eight-miRNA signature as a potential biomarker for predicting survival in lung adenocarcinoma. J Transl Med. 2014;12:159.

45. Ma J, Mannoor K, Gao L, et al. Characterization of microRNA transcriptome in lung cancer by next-generation deep sequencing. Mol Oncol. 2014;8(7):1208-1219.

46. Yu H, Jiang L, Sun C, et al. Decreased circulating miR-375: a potential biomarker for patients with non-small-cell lung cancer. Gene. 2014;534(1):60-65.

47. Li Y, Liang L, Zhang CY. Isothermally sensitive detection of serum circulating miRNAs for lung cancer diagnosis. Anal Chem. 2013;85(23): 11174-11179.

48. Rani S, Gately K, Crown J, O'Byrne K, O’Driscoll L. Global analysis of serum microRNAs as potential biomarkers for lung adenocarcinoma. Cancer Biol Ther. 2013;14(12):1104-1112.

49. Kaduthanam S, Gade S, Meister M, et al. Serum miR-142-3p is associated with early relapse in operable lung adenocarcinoma patients. Lung Cancer. 2013;80(2):223-227.

50. Mitchell PS, Parkin RK, Kroh EM, et al. Circulating microRNAs as stable blood-based markers for cancer detection. Proc Natl Acad Sci USA. 2008;105(30):10513-10518.

51. Sourvinou IS, Markou A, Lianidou ES. Quantification of circulating miRNAs in plasma: effect of preanalytical and analytical parameters on their isolation and stability. J Mol Diagn. 2013;15(6):827-834. 
52. Cheng HH, Yi HS, Kim Y, et al. Plasma processing conditions substantially influence circulating microRNA biomarker levels. PLoS One. 2013;8(6):e64795.

53. Heegaard NH, Schetter AJ, Welsh JA, Yoneda M, Bowman ED, Harris CC. Circulating micro-RNA expression profiles in early stage nonsmall cell lung cancer. Int J Cancer. 2012;130(6):1378-1386.

54. Keller A, Backes C, Leidinger P, et al. Next-generation sequencing identifies novel microRNAs in peripheral blood of lung cancer patients. Mol Biosyst. 2011;7(12):3187-3199.

55. Wang Y, Gu J, Roth JA, et al. Pathway-based serum microRNA profiling and survival in patients with advanced stage non-small cell lung cancer. Cancer Res. 2013;73(15):4801-4809.

56. Lin Q, Chen T, Lin Q, et al. Serum miR-19a expression correlates with worse prognosis of patients with non-small cell lung cancer. J Surg Oncol. 2013;107(7):767-771.

57. Sanfiorenzo C, Ilie MI, Belaid A, et al. Two panels of plasma microRNAs as non-invasive biomarkers for prediction of recurrence in resectable NSCLC. PLoS One. 2013;8(1):e54596.

58. Chen Q, Si Q, Xiao S, et al. Prognostic significance of serum miR-17-5p in lung cancer. Med Oncol. 2013;30(1):353.

59. Fortunato O, Boeri M, Verri C, et al. Assessment of circulating microRNAs in plasma of lung cancer patients. Molecules. 2014;19(3): 3038-3054.

60. Rani S, Gately K, Crown J, O’Byrne K, O’Driscoll L. Global analysis of serum microRNAs as potential biomarkers for lung adenocarcinoma. Cancer Biol Ther. 2013;14(12):1104-1112.

61. Mozzoni P, Banda I, Goldoni M, et al. Plasma and EBC microRNAs as early biomarkers of non-small-cell lung cancer. Biomarkers. 2013;18(8):679-686.

62. Tang D, Shen Y, Wang M, et al. Identification of plasma microRNAs as novel noninvasive biomarkers for early detection of lung cancer. Eur J Cancer Prev. 2013;22(6):540-548.

63. Ulivi P, Foschi G, Mengozzi M, et al. Peripheral blood miR-328 expression as a potential biomarker for the early diagnosis of NSCLC. Int J Mol Sci. 2013;14(5):10332-10342.

64. Zheng D, Haddadin S, Wang Y, et al. Plasma microRNAs as novel biomarkers for early detection of lung cancer. Int J Clin Exp Pathol. 2011;4(6):575-586.

65. Wu R, Jiang Y, Wu Q, et al. Diagnostic value of microRNA-21 in the diagnosis of lung cancer: evidence from a meta-analysis involving 11 studies. Tumour Biol. 2014;35(9):8829-8836.

66. Shen Y, Wang T, Yang T, et al. Diagnostic value of circulating microRNAs for lung cancer: a meta-analysis. Genet Test $\mathrm{Mol}$ Biomarkers. 2013;17(5):359-366.

67. Bianchi F, Nicassio F, Marzi M, et al. A serum circulating miRNA diagnostic test to identify asymptomatic high-risk individuals with early stage lung cancer. EMBO Mol Med. 2011;3(8):495-503.

68. Skrzypski M, Czapiewski P, Goryca K, et al. Prognostic value of microRNA expression in operable non-small cell lung cancer patients. Br J Cancer. 2014;110(4):991-1000.
69. Li ZH, Zhang H, Yang ZG, Wen GQ, Cui YB, Shao GG. Prognostic significance of serum microRNA-210 levels in non-small-cell lung cancer. J Int Med Res. 2013;41(5):1437-1444.

70. Franchina T, Amodeo V, Bronte G, et al. Circulating miR-22, miR-24 and miR-34a as novel predictive biomarkers to pemetrexed-based chemotherapy in advanced non-small cell lung cancer. J Cell Physiol. 2014;229(1):97-99.

71. Patnaik SK, Yendamuri S, Kannisto E, Kucharczuk JC, Singhal S, Vachani A. MicroRNA expression profiles of whole blood in lung adenocarcinoma. PLoS One. 2012;7(9):e46045.

72. Liao QB, Guo JQ, Zheng XY, et al. Test performance of sputum microRNAs for lung cancer: a meta-analysis. Genet Test Mol Biomarkers. 2014;18(8):562-567.

73. Shin YM, Yun J, Lee OJ, et al. Diagnostic value of circulating extracellular miR-134, miR-185, and miR-22 levels in lung adenocarcinoma-associated malignant pleural effusion. Cancer Res Treat. 2014;46(2):178-185.

74. Xie Y, Todd NW, Liu Z, et al. Altered miRNA expression in sputum for diagnosis of non-small cell lung cancer. Lung Cancer. 2010;67(2): $170-176$.

75. Li N, Ma J, Guarnera MA, Fang H, Cai L, Jiang F. Digital PCR quantification of miRNAs in sputum for diagnosis of lung cancer. $J$ Cancer Res Clin Oncol. 2014;140(1):145-150.

76. Shen J, Liao J, Guarnera MA, et al. Analysis of MicroRNAs in sputum to improve computed tomography for lung cancer diagnosis. J Thorac Oncol. 2014;9(1):33-40.

77. Sato-Kuwabara Y, Melo SA, Soares FA, Calin GA. The fusion of two worlds: non-coding RNAs and extracellular vesicles - diagnostic and therapeutic implications (review). Int J Oncol. 2015;46(1):17-27.

78. Mello SA, Sugimoto H, O’Connell JT, et al. Cancer exosomes perform cell-independent microRNA biogenesis and promote tumorigenesis. Cancer Cell. 2014;26(5):707-721.

79. Rabinowits G, Gerçel-Taylor C, Day JM, Taylor DD, Kloecker GH. Exosomal microRNA: a diagnostic marker for lung cancer. Clin Lung Cancer. 2009;10(1):42-46.

80. Frydrychowicz M, Kolecka-Bednarczyk A, Madejczyk M, Yasar S, Dworacki G. Exosomes - structure, biogenesis, and biological role in non-small-cell lung cancer. Scand J Immunol. Epub October 30, 2014.

81. Leidinger P, Backes C, Dahmke IN, et al. What makes a blood cell based miRNA expression pattern disease specific? - a miRNome analysis of blood cell subsets in lung cancer patients and healthy controls. Oncotarget. 2014;5(19):9484-9497.

82. Rodríguez M, Silva J, López-Alfonso A, et al. Different exosome cargo from plasma/bronchoalveolar lavage in non-small-cell lung cancer. Genes Chromosomes Cancer. 2014;53(9):713-724.

83. Nana-Sinkam SP, Croce CM. Clinical applications for microRNAs in cancer. Clin Pharmacol Ther. 2012;93(1):98-104.
Current Biomarker Findings

\section{Publish your work in this journal}

Current Biomarker Findings is an international, peer-reviewed, open access journal publishing original research, reports, reviews and commentaries on all areas of biomarker research. The manuscript management system is completely online and includes a very quick and fair peer-review system. Visit http://www.dovepress.com/testimonials.php to read real quotes from published authors. 